\title{
Graft and preparation issues during esophageal reconstruction
}

\begin{abstract}
The substantial improvement in chemotherapy and radiation regimens has led to increasing the rate of surgical intervention in patients with esophageal cancer. The gastric graft is the preferred conduit to establish the gut continuity after esophagectomy for cancer. However, prior gastric surgery and gastric pathological conditions may pose intraoperative difficulties in a subset of patients to safely create the future gastric graft. In these particular situations, alternative options should be considered using an available organ as an alternative conduit. The colon and jejunum grafts are usually used as an alternative conduit to complete reconstruction after esophagectomy when the stomach is unusable. Therefore, the esophageal surgeons should acquire surgical skills and experience to be adept at managing intraoperative difficulties with the conduit preparation.
\end{abstract}

Keywords: gastric conduit, prior gastric surgery, colon interposition, jejuna graft, graft ischemia
Volume II Issue 5 - 2020

\author{
Abdelkader Boukerrouche \\ Department of Digestive Surgery, University of Algiers, Algeria
}

Correspondence: Abdelkader Boukerrouche, Department of Digestive Surgery, Hospital of Beni-Messous, University of Algiers, Algiers, Algeria, Tel +21366I 2272 98,

Email aboukerrouche@yahoo.com

Received: June 28, 2020 | Published: September 28, 2020

\section{History of prior surgery}

Prior gastric surgery can preclude the use of the stomach as a graft for esophageal reconstruction after esophagectomy. The blood supply to the gastric conduit is mainly assured by the right gastroepiploic artery. So, any injury to this vessel precludes the safety of gastric graft creation. The gastrostomy feeding tube is often avoided in patients planned for esophageal surgery, and feeding jejunostomy is usually performed during esophageal reconstruction. However, precautions should be taken when dissecting and closing gastrostomy. ${ }^{1}$ Prior gastric surgical procedures can render the stomach unusable as a future graft for esophageal reconstruction after esophagectomy. The gastroepiploic arcade can be disrupted or injured, either purposefully or inadvertently, when mobilizing the greater curvature during fundoplication procedure as reported, the stomach can be used as a graft after antireflux and hiatal hernia procedures, however, the operative time was increased with high-risk for developing postoperative complications. ${ }^{2,3}$ Bariatric surgical procedures remain a challenge during the surgical treatment of esophageal cancer, and the remnant stomach is rarely usable as a future conduit. ${ }^{4-8}$ Laparoscopic sleeve gastrectomy is the most popular and performed procedure amongst weight-loss operations. ${ }^{9}$ The vascular supply of the remaining gastric tube following sleeve gastrectomy lies on the left and right gastric arteries along the lesser curvature, rending the gastric tube unusable as a conduit for esophageal reconstruction. A gastric graft after the Roux-en-Y gastric bypass can be safely created; however, operative time was increased related to dissection and additional required anastomoses. Furthermore, embolization of the gastroduodenal artery, as an interventional treatment for complicated ulcer with upper gastrointestinal bleeding render stomach unusable because the right gastroepiploic artery arises from the gastroduodenal artery. ${ }^{10}$ Also, extensive gastric resection to optimize tumor removal of the distal esophageal results in the remnant stomach with insufficient length to reach the neck.

\section{Alternative graft options}

Choosing a graft for esophageal reconstruction following esophagectomy depends on the distance of reconstruction, the available conduit, and the surgeon's familiarity or preference with a surgical technique. However, deep-knowledge and familiarity with alternative graft options are key for a successful esophageal reconstruction. To address this issue, many institutions privilege interspecialty collaboration including thoracic surgeons, general surgical oncologists, colorectal, and/or plastic surgeons.

The jejunum has some features including luminal size which matches well with the esophagus lumen, the reliable blood supply, and the less proneness for the disease. The jejunum can be used as a pedicled transplant or free jejunal graft or supercharged pedicled graft with microvascular anastomosis to the internal mammary vessels. ${ }^{11}$ The jejunal graft is often used for segmental reconstruction with a short distance, especially during the reconstruction of the cervical esophagus.

The colon is the first digestive organ used in esophageal reconstructive surgery. ${ }^{12}$ The advantages of the colon include increased length that can be mobilized on its vascular pedicle and resistance to gastric acid injury. The disadvantages of colon interposition include the need to perform additional anastomoses, high risk of graft ischemia compared to gastric graft, and long-term dilatation resulting in redundancy. Either the right or left colon can be used, however, the left colon has a more constant arterial supply and smaller diameter with less prone to dilatation, compared to the right colon. Furthermore, the left colonic interposition is slightly preferred by many surgeons because of the lower risk of graft ischemia. The colon segment to be harvested is based on the distance of reconstruction and the adequate blood supply. In addition, the transverse colon is often harvested to provide further length in both right and left colon. ${ }^{12,13}$ The colon exploration is required before surgery, especially 
in patients with a history of inflammatory bowel disease or highrisk of disease including malignancy, diverticular disease, and even polyposis. The preoperative colonoscopy is performed routinely, and other modalities such as imaging or angiography can be included to delineate the arterial vascular arcades, especially in patients with a history of colon surgery. Colon preparation should be instituted in where colonic interposition is planned or considered as an alternative option intra operatively.

Overall, the decision to which colon could be used is made intra operatively after vascular clamping testing to assess the adequacy of the selected colon segment. ${ }^{14}$ Importantly, the colon graft should be used in isoperistaltic fashion. According to the colon segment and its blood supply; there are six main selection patterns of grafts (Table 1).

Table I Types of colon graft

\begin{tabular}{|c|c|c|}
\hline Blood supply & Colon graft & Direction \\
\hline Ileocolic artery & Ascending+transverse & Antiperistalsis \\
\hline Right colic artery & $\begin{array}{l}\text { lleum+ascending } \\
\text { Ascending+transverse }\end{array}$ & $\begin{array}{l}\text { Isoperistalsis } \\
\text { Antiperistalsis }\end{array}$ \\
\hline Middle colic artery & $\begin{array}{l}\text { Ascending+transverse } \\
\text { ascending+transverse }\end{array}$ & $\begin{array}{l}\text { Antiperistalsiss } \\
\text { Isoperistalsis }\end{array}$ \\
\hline Left colic artery & Transverse+descending & Isoperistalsis \\
\hline
\end{tabular}

The graft of reconstruction can be pulled up through various routes namely the posterior mediastinum, the substernal tunnel, and the subcutaneous route. The subcutaneous route is the longest, with the sharpest angle of the cervical and abdominal extremities, resulting in a high risk of graft ischemia and necrosis. This placement site of the graft is reserved when other options are not suitable. ${ }^{13}$ The posterior mediastinum is the shortest and most direct route, with a minimized risk of ischemia. ${ }^{15}$ The posterior mediastinum is preferred for immediate reconstruction. However, significant scarring after mediastinal dissection may preclude the safe re-access of the posterior mediastinum. ${ }^{16}$ The substernal route has been advocated in delayed reconstruction and palliative surgery, and when the posterior mediastinum is not readily accessible ${ }^{16}$ Creating the substernal tunnel does not require a thoracic incision, thereby minimizing pulmonary complications. This route has the biggest disadvantage of the potential risk of graft compression in the cervical region leading to mechanical graft ischemia. Thus, it is advisable to enlarge the thoracic inlet by removing the left half of the manubrium and the internal third of the left clavicle. Additionally, widening the thoracic inlet allows access to the left internal mammary vessels to perform micro vessel anastomosis.

\section{Intraoperative issues}

Regarding the graft viability, difficulty, and concerns about the graft blood supply can arise intra operatively. The graft ischemia is the most dreaded complication occurring during esophageal reconstruction. The fluorescence angiography or Doppler is useful to assess the graft blood supply. ${ }^{17,18}$ To this end, 5 to $10 \mathrm{mg}$ of indocyanine green is administrated intravenously, and the graft is then assessed for perfusion in a qualitative fashion, as the indocyanine green is distributed in the tissue. ${ }^{19}$ Once confirmed, several treatment approaches are available to adequately deal with graft ischemia. The arterial flow augmentation and venous drainage improvement are mainly performed by anastomosing the graft mesenteric vessels to the left internal mammary artery.
The improvement of graft perfusion can clinically be ascertained confirmed by clearance of Congestion and cyanosis and appearance of adequate pulsation of the graft vessel. Also, this blood flow improvement can be performed by techniques previously described. ${ }^{20}$

If technical conditions are not favourable to perform graft supercharge, other options can be considered. Selecting another conduit and achieving reconstruction is an alternative in hemodynamically stable patients with fewer risk factors and short operative time. Whereas, in high-risk patients with hemodynamic instability, delaying the reconstruction process is the optimal option with removing the ischemic graft, diverting the cervical esophagus, performing feeding jejunostomy, and transferring patients to intensive care for optimization. Further reconstruction should be considered in patients with optimized clinical conditions. Another option that can be considered in sub acute graft ischemia is to leave the patient in discontinuity for 24 to 72 hours, and then return to the operating room to re-evaluate the graft viability. Colon interposition is more demanding and the surgeon should be more familiar with it. The surgeon should choose the appropriate approach to deal with the colon graft ischemia intra operatively. Overall, colon interposition was associated with a high risk of graft ischemia. Therefore, prevention is the best way, including preoperative identification and optimization of the highrisk patient (comorbidities), and careful selection of colon segment with avoiding the weak vascular points. Also, precautions should be taken while pulling the graft to the neck, avoiding twist, kicking, and mechanical compression. When the substernal route is used, the thoracic inlet should be enlarged to prevent graft compression.

Finally, Surgery remains a part of the multimodal treatment of esophageal cancer. To achieve successful reconstruction following oesophagectomy, knowledge of managing a difficult graft and having a surgical skill with alternative graft options, how to deal are required to optimize the dealing with intraoperative issues

\section{Acknowledgments}

None.

\section{Conflicts of interest}

The authors declare that they have no conflicts of interest to disclose.

\section{Financial disclosure}

None.

\section{References}

1. Wright GP, Foster SM, Chung MH. Esophagectomy in patients with prior percutaneousgastrostomy tube placement. Am J Surg. 2014;207(3):361365.

2. Shen KR, Harrison-Phipps KM, Cassivi SD, et al. Esophagectomy after anti-reflux surgery. J Thorac Cardiovasc Surg. 2010;139(4):969-975.

3. Chang AC, Lee JS, Sawicki KT, et al. Outcomes after esophagectomy in patients with prior antireflux or hiatal hernia surgery. Ann Thorac Surg. 2010;89(4):1015-1023

4. Rossidis G, Browning R, Hochwald SN, et al. Minimally invasive esophagectomy is safe in patients with previous gastric bypass. Surg Obes Relat Dis. 2014;10(1):95-100. 
5. Kuruba R, Jawad M, Karl RC, et al. Technique of resection of esophageal adenocarcinoma after Roux-en-Y gastric bypass and literature review of esophagogastric tumors after bariatric procedures. Surg Obes Relat Dis. 2009;5(5):576-581.

6. Allen JW, Leeman MF, Richardson JD. Esophageal carcinoma following bariatric procedures. JSLS. 2004;8(4):372-375.

7. Nguyen NT, Tran C, Gelfand DV, et al. Laparoscopic and thoracoscopic Ivor Lewis esophagectomy after Roux-en-Y gastric bypass. Ann Thorac Surg. 2006;82(5):1910-1913.

8. Marino KA, Weksler B. Esophagectomy after weight-reduction surgery. Thorac Surg Clin. 2018;28(1):53-58.

9. English WJ, DeMaria EJ, Brethauer SA, et al. American Society for Metabolic and Bariatric Surgery estimation of metabolic and bariatric procedures performed in the United States in 2016. Surg Obes Relat Dis. 2018;14(3):259.

10. Shin JH. Recent update of embolization of upper gastrointestinal tract bleeding. Korean J Radiol. 2012;13(Suppl 1):S31-S39.

11. Blackmon SH, Correa AM, Skoracki R, et al. Supercharged pedicled jejunal interposition for esophageal replacement: a 10-year experience. Ann Thorac Surg. 2012;94(4):1104-1111.

12. Bakshi A, Sugarbaker DJ, Burt BM. Alternative conduits for esophageal replacement. Ann Cardiothorac Surg. 2017;6(2):137-143.
13. Boukerrouche A. Colon reconstruction and esophageal reconstructive surgery. Med Clin Rev. 2016;2:27.

14. Koh PS, Turnbull G, Attia E. Esophageal Replacement for Caustic StrictureABrief Review. Adv Res Gastroentero Hepatol. 2017;3(5):10.19080/AR

15. Koh P, Turnbull G, Attia E, et al. Functional assessment of the cervical esophagus after gastric transposition and cervical esophagogastrostomy. Eur J Cardiothorac Surgery. 2004;25(4):480-485.

16. Boukerrouche A. Colonic Esophageal Reconstruction by Substernal Approach for Caustic Stricture: What is the Impact of the Enlargement of the Thoracic Inlet on Cervical Anastomotic Complications? Journal of Surgery. 2016;10(2):140-145.

17. Sarkaria IS, Bains MS, Finley DJ, et al. Intraoperative near-infrared fluorescence imaging as an adjunct to robotic assisted minimally invasive esophagectomy. Innovations (Phila). 2014;9(5):391-393.

18. Zehtner J, DeMeester SR, Alicuben ET, et al. Intraoperative assessment of perfusion of the gastric graft and correlation with anastomotic leaks after esophagectomy. Ann Surg. 2015;262(1):74-78.

19. Yukaya T, Saeki H, Kasagi Y, et al. Indocyanine green fluorescence angiography for quantitative evaluation of gastric tube perfusion in patients undergoing esophagectomy. J Am Coll Surg. 2015;221:e37-e42.

20. Shirakawa Y, Naomoto Y, Sakurama K, et al. Colonic interposition and supercharge for esophageal reconstruction. Arch Surg. 391(1):19-23. 